\title{
A New Method for Equivalent Acceleration of JEDEC Moisture Sensitivity Levels
}

\author{
Daniel Shi ${ }^{1}$, Xuejun Fan ${ }^{2,3}$, Bin Xie ${ }^{1}$ \\ ${ }^{1}$ Hong Kong Applied Science \& Technology Research Institute, Hong Kong Science Park, Shatin, Hong Kong, PRC \\ Email: danielshi@astri.org \\ ${ }^{2}$ Department of Mechanical Engineering, Lamar University, PO Box 10028, Beaumont, TX 77710, USA \\ Email: xuejun.fan@lamar.edu \\ ${ }^{3}$ Department of Engineering Mechanics, South China University of Technology, Guangzhou 510640, People's Republic of \\ China
}

\begin{abstract}
In order to devise an equivalent accelerated moisture sensitivity test, the JEDEC specification J-STD-020C has recommended an accelerated preconditioning time of $40 \mathrm{hrs}$ exposure under $60^{\circ} \mathrm{C} / 60 \% \mathrm{RH}$, which is considered equivalent to the standard moisture sensitivity level 3 (MSL-3) of 216hrs soak time under $30^{\circ} \mathrm{C} / 60 \% \mathrm{RH}$. However, the existing methodology for the accelerated moisture sensitivity test was developed based on the equivalency of local moisture concentration at the interest of location for leaded packages only. The failure mechanism is restricted to the potential delamination between mold compound and leadframe. In addition, such an equivalency requires the activation energy of molding compound for moisture diffusion in the range of $0.4-0.48 \mathrm{eV}$. This paper introduces a new method to accelerate JEDEC/IPC moisture sensitivity level testing. The methodology is developed based on the equivalency of both local moisture concentration and overall moisture distribution of packages. The local moisture concentration equivalency ensures identical adhesion strength and vapor pressure at interfaces of the interest, and the overall moisture distribution equivalency results in the same condition of applied driving forces, such as thermal and hygroscopic stresses, during reflow. In our previous study [1], this methodology was applied to a molded matrix array package, and an accelerated soak time subjected to $60^{\circ} \mathrm{C} / 60 \% \mathrm{RH}$ was established. In this paper, the further reduction of soak time using $85^{\circ} \mathrm{C} / 60 \% \mathrm{RH}$ is investigated. An ultra-thin stacked-die chip scale package (CSP) is used as the test vehicle. Extensive experiments have been carried out to obtain the failure rate as function of soak time under various environmental conditions. Finite element analysis was performed to obtain the equivalency conditions. According to finite element modeling results, it has been found that, at $70 \mathrm{hrs}$ under $60^{\circ} \mathrm{C} / 60 \% \mathrm{RH}$ and $45 \mathrm{hrs}$ under $85^{\circ} \mathrm{C} / 60 \% \mathrm{RH}$, respectively, both the local moisture concentration at critical interface and overall moisture distribution of package become identical to that under the standard MSL-3. Such an equivalency of the new accelerated test conditions has been proven by the test results. Failure site and failure mode indicates that the proposed accelerated tests are well correlated with the standard MSL-3. The new methodology can be extended to other packages.
\end{abstract}

\section{Introduction}

Cracking and delamination subjected to moisture is one of key failure modes for plastic electronics packages at soldering reflow. The failure mechanism is due to the combined effects of thermo-mechanical stresses, hygroscopic stresses, vapor pressure, material softening, and adhesion degradation. For ultra-thin chip scale packages (CSP) in telecommunications, moisture absorption in a package reaches saturation level before the required soak time due to the thin feature of such a package. Therefore, meeting the package moisture sensitivity requirements without cracking and delamination becomes a key concern in package development. The higher reflow temperature required for lead-free packaging and the new materials used for wafer-level packaging result in increased reliability concerns for these plastic packages.

To mimic the same failure mode within a short time period, the joint JEDEC/IPC industry standard J-STD-020 has defined and outlined the moisture/reflow sensitivity testing for plastic surface mount devices (SMDs) [2]. To classify the moisture sensitivity rating of plastic packages, this test specification has established various parameters of exposure conditions, i.e., ambient temperature, relative humidity, soak time and reflow profile. Moisture sensitivity test is a precursor test to most reliability tests. However, the duration required for this standard preconditioning is too long, which is unproductive and costly. For example, the moisture sensitivity level 3 (MSL-3) requires 216hrs moisture preconditioning under $30^{\circ} \mathrm{C} / 60 \% \mathrm{RH}$. The long test time has significantly hindered the time-to-market for new product development and new material evaluation.

In order to devise an equivalent accelerated moisture sensitivity test, JEDEC specification J-STD-020 has recommended an accelerated preconditioning of $40 \mathrm{hrs}$ exposure under $60^{\circ} \mathrm{C} / 60 \% \mathrm{RH}$, which is equivalent to the standard MSL-3 preconditioning. Such an accelerated test reduces the total required moisture soak time for MSL-3 by approximately a factor of five. However, the equivalency was established for leaded packages only with predominant failure mechanism of interface delamination between mold compound and leadframe. Furthermore, the activation energy of molding compound for diffusion must be in the range of $0.4-0.48 \mathrm{eV}$ in order to apply the 'equivalent' soaking time. The methodology for accelerated moisture sensitivity test was developed based on the equivalency of local moisture concentration at the interest of location [3-4].

Due to the thin profile of most CSP packages, moisture diffusion is faster and moisture concentration at critical interfaces becomes saturated early. The test method based on the equivalency of local moisture concentration cannot define the accurate accelerated soak time for saturation conditions. Also in the existing accelerated test, it has been assumed that the failure of cracking and delamination is predominantly controlled by local moisture concentration, which will induce vapor pressure and reduce interfacial adhesion. However, the moisture-induced failure during reflow is also affected by the 
thermal stresses due to thermal mismatch and hygrostresses due to hygroscopic swelling mismatch.

This paper introduces a new methodology of the accelerated JEDEC/IPC moisture sensitivity level test. The methodology is developed based on the equivalency of both local moisture concentration (i.e., equivalency of vapor pressure) and overall moisture distribution (i.e., equivalency of thermal stresses and hygrostresses) of packages. Finite element analysis (FEA) is applied for moisture diffusion and vapor pressure analysis under various environmental conditions to determine the equivalent soak times. The equivalency of the new test conditions is proven by moisture/reflow experiments under various soak times.

\section{New Moisture Accelerated Test Methodology}

The JEDEC/IPC moisture sensitivity/reflow test consists of two stages. Stage I is the process of moisture soaking, in which a specific combination between ambient temperature, relative humidity and soak time is defined to mimic factory environment during storage before surface mounting, as shown in Fig. 1.

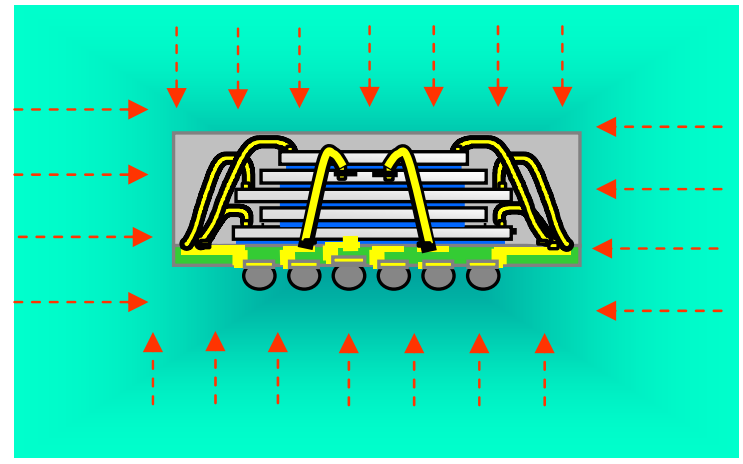

(a)
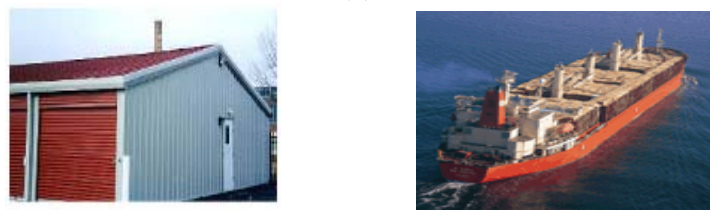

(b)

Fig. 1: (a) Moisture soak in the stage I of JEDEC/IPC moisture sensitivity test, (b) moisture soak of plastic packages during storage and shipping

Stage II is the process of rapid heating to simulate the surface mounting soldering reflow process, as shown in Fig. 2. The entire packages with lead-free materials are exposed to an elevated temperature environment with peak temperature as high as $260^{\circ} \mathrm{C}$ or even $270^{\circ} \mathrm{C}$.

During surface mounting, thermal stresses are developed due to thermal mismatch. [5-7]. The thermal strain, $\varepsilon_{\mathrm{T}}$, at the soak temperature can be expressed as

$$
\varepsilon_{\mathrm{T}}=\alpha \Delta T
$$

where $\alpha$ is the coefficient of thermal expansion (CTE), and $\Delta T$ is the temperature change. Similarly, hygroscopic stresses are developed due to hygroscopic swelling mismatch [8-12]. The hygroscopic swelling strain, $\varepsilon_{\mathrm{H}}$, at the soaking humidity condition can be expressed as

$$
\varepsilon_{\mathrm{H}}=\beta C
$$

where $\beta$ is the coefficient of hygroscopic swelling, and $C$ is the moisture concentration. During the soak, the moisture condenses in the micropores or free volumes of porous materials. The moisture vaporization generates high vapor pressure [13-17]. Generally, the driving forces inducing failures are thermal stress, hygro-stress and vapor pressure in the moisture sensitivity level test, which can be described as

$\sigma=\sigma_{\mathrm{T}}+\sigma_{\mathrm{H}}+\mathrm{P}$

where $\sigma$ is total driving forces inducing failures, $p$ is the vapor pressure.

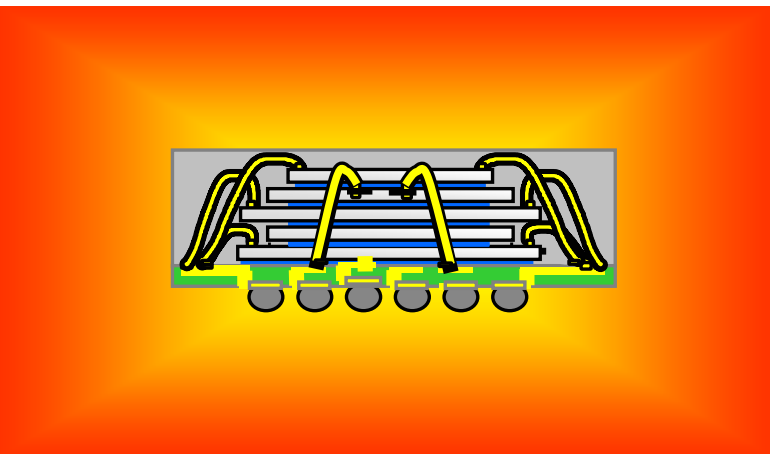

(a)

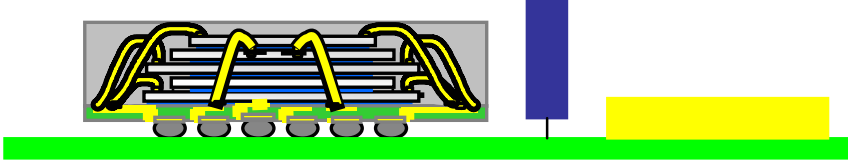

(b)

Fig. 2: (a) Rapid heating in the stage II of JEDEC/IPC moisture sensitivity test, (b) surface mounting soldering reflow process

The existing methodology for accelerated moisture sensitivity test was developed based on the equivalency of local moisture concentration at the critical interface. Local moisture concentration determines local vapor pressure and interfacial adhesion. The equivalency of local moisture concentration can ensure the equivalency of local vapor pressure and interfacial adhesion theoretically. However, the equivalency of local moisture concentration is not enough to ensure the equivalency of local thermal stress and hygrostress, because the local thermal stress and hygro-stress are affected by the overall temperature and moisture distributions of the whole electronic package. Therefore, to ensure the equivalency of all driving forces (i.e., thermal stress, hygrostress and vapor pressure) between the standard and accelerated moisture sensitivity level tests, not only the local moisture concentration at the critical interface but also the overall temperature and moisture distributions of the whole electronic package should be equivalent to achieve the equivalency of failure mode and failure rate.

This paper introduces a new methodology that can accelerate the IPC/JEDEC moisture sensitivity level test of an ultra-thin stacked-die CSP. The methodology is mainly developed based on the equivalency of both local moisture concentration and the overall moisture distribution. The local moisture concentration equivalency would be established first 
to ensure the equivalency of vapor pressure. Further, in order to ensure the equivalency of hygro-stress within different soak conditions, the overall moisture distribution would be indistinguishable. If the level of total driving forces is below the level of interface adhesion strength, the failure of cracking/delamination would not occur. Otherwise, the failure would occur. If the start points of cracking/delamination occurrence of standard and accelerated tests are in the same level, the failure rates between two tests are treated as equivalency, as shown in Fig. 3.

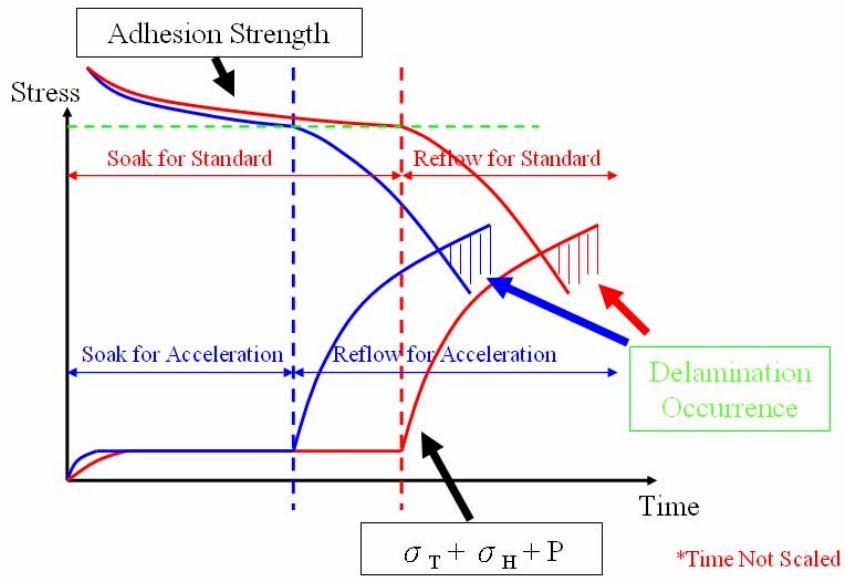

Fig. 3: Methodology of new moisture accelerated test

To implement the new methodology, a novel direct concentration approach (DCA) was developed and applied in this study to determine the equivalency of local moisture concentration as well as the overall moisture distribution under $30^{\circ} \mathrm{C} / 60 \% \mathrm{RH}, \quad 60^{\circ} \mathrm{C} / 60 \% \mathrm{RH}$ and $85^{\circ} \mathrm{C} / 60 \% \mathrm{RH}$, respectively. The approach can simulate the moisture diffusion of the package under both constant and varying ambient temperature and humidity conditions $[18,19]$. In the approach, the moisture concentration is used as the field variable directly and constraint equation is used to ensure the interfacial continuous condition. To validate the new methodology and modeling results, the moisture/reflow tests were performed under the conditions of MSL-3 and 30hrs-, $45 \mathrm{hrs}-, 60 \mathrm{hrs}-, 75 \mathrm{hrs}-, 88 \mathrm{hrs}-60^{\circ} \mathrm{C} / 60 \% \mathrm{RH}$ and $30 \mathrm{hrs}-, 45 \mathrm{hrs}-$ , $60 \mathrm{hrs}-85^{\circ} \mathrm{C} / 60 \% \mathrm{RH}$, respectively. The sample size was 48 units for each condition. The experimental procedures used were: Firstly, the thru-scanning acoustic microscope (TSAM) was adopted for the initial inspection to ensure no cracking/delamination occurring before moisture/reflow test. All the packages were baked for $24 \mathrm{hrs}$ at $125^{\circ} \mathrm{C}$ to remove the initial moisture inside. Secondly, the packages absorbed the moisture under the above conditions. After the moisture soak, the packages were subjected to 3 cycles of JEDEC standard reflow with the peak temperature of $260^{\circ} \mathrm{C}$. Lastly, the TSAM was used again for the final inspection to determine the failure rate. A 3D ultra-thin stacked-die CSP was employed as test vehicle for both numerical simulations and experimental validation, as shown in Fig. 4. It consists of molding compound (MC), silicon die, die-attach film, solder resist (SR) and bismaleimide-triazine (BT) core. In the previous study, most cracking/delamination failure of die-attach film was found in the bottom film. Therefore, the study of moisture distribution and driving forces inducing cracking/delamination focused on the bottom film in this paper.

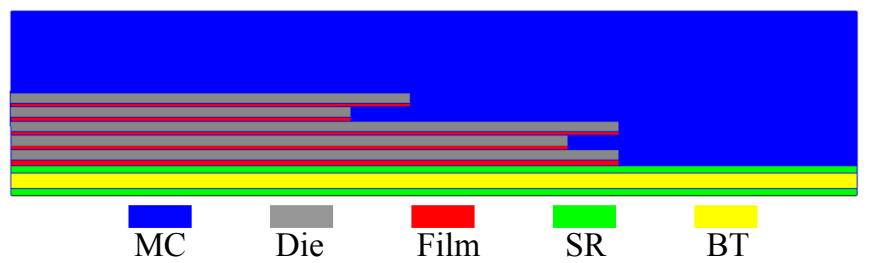

Fig. 4: The schematic structure of test vehicle

\section{Modeling and Simulation}

1. Moisture Diffusion Modeling

The moisture soak histories at the bottom film/substrate interface under $30^{\circ} \mathrm{C} / 60 \% \mathrm{RH}, \quad 60^{\circ} \mathrm{C} / 60 \% \mathrm{RH}$ and $85^{\circ} \mathrm{C} / 60 \% \mathrm{RH}$ are shown in Fig 5. The local moisture concentration at the interface is saturated after $100 \mathrm{hrs}$ under $30^{\circ} \mathrm{C} / 60 \% \mathrm{RH}, 40 \mathrm{hrs}$ under $60^{\circ} \mathrm{C} / 60 \% \mathrm{RH}$ and $25 \mathrm{hrs}$ under $85^{\circ} \mathrm{C} / 60 \%$ RH. It means from $40 \mathrm{hrs}$ under $60^{\circ} \mathrm{C} / 60 \% \mathrm{RH}$ and $25 \mathrm{hrs}$ under $85^{\circ} \mathrm{C} / 60 \% \mathrm{RH}$, the local moisture concentration is equivalent with that under MSL-3. However, it does not mean $40 \mathrm{hrs}$ under $60^{\circ} \mathrm{C} / 60 \% \mathrm{RH}$ and $25 \mathrm{hrs}$ under $85^{\circ} \mathrm{C} / 60 \% \mathrm{RH}$ are equivalent with MSL-3.

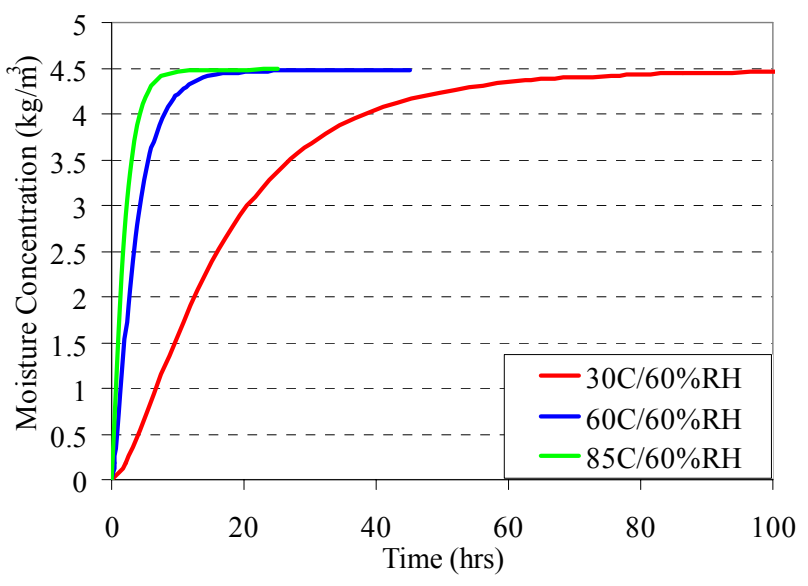

Fig. 5: Moisture soak histories under $30^{\circ} \mathrm{C} / 60 \% \mathrm{RH}$, $60^{\circ} \mathrm{C} / 60 \% \mathrm{RH}$ and $85^{\circ} \mathrm{C} / 60 \% \mathrm{RH}$

To determine the equivalent soak times under $60^{\circ} \mathrm{C} / 60 \% \mathrm{RH}$ and $85^{\circ} \mathrm{C} / 60 \% \mathrm{RH}$, the overall moisture distribution in the package would be investigated. FEA of moisture diffusion was performed for MSL-3 and 45hrs-, $70 \mathrm{hrs}-60^{\circ} \mathrm{C} / 60 \% \mathrm{RH}$ and $25 \mathrm{hrs}-, 45 \mathrm{hrs}-85^{\circ} \mathrm{C} / 60 \% \mathrm{RH}$. The modeling results are shown in Fig. 6. Comparing Fig. 6(a) with Fig. 6(b), it is observed that although the local moisture concentration at bottom film reaches the same under $45 \mathrm{hrs}-$ $60^{\circ} \mathrm{C} / 60 \% \mathrm{RH}$ as that under MSL-3, the overall equivalency of moisture distribution is not reached yet at this time. Not only the local moisture concentration at the bottom film/substrate interface but also overall moisture distribution under $70 \mathrm{hrs}-$ $60^{\circ} \mathrm{C} / 60 \% \mathrm{RH}$ are equivalent with that of soak for MSL-3. Similarly, the overall equivalency of moisture distribution is not reached yet under MSL-3 and $25 \mathrm{hrs}-85^{\circ} \mathrm{C} / 60 \% \mathrm{RH}$, as 
shown in Fig. 6(a) and (d). Until soak for 45hrs$85^{\circ} \mathrm{C} / 60 \% \mathrm{RH}$, the overall moisture distribution is equivalent with that of soak for MSL-3, as shown in Fig. 6(e) and (a).

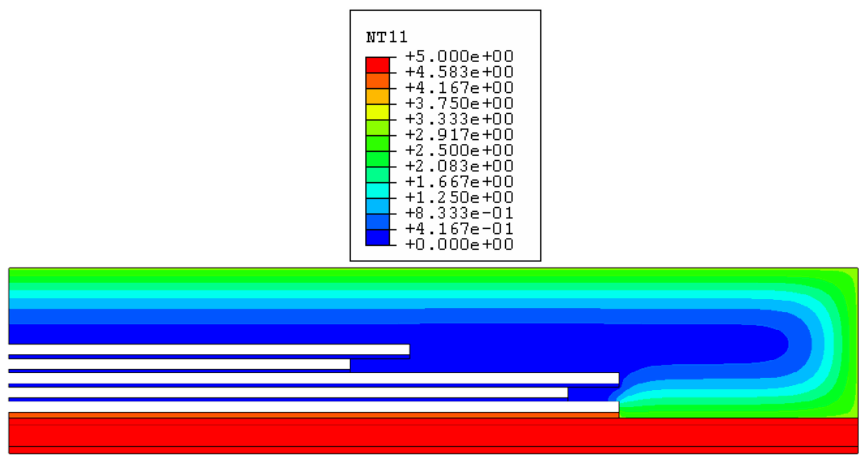

(a)

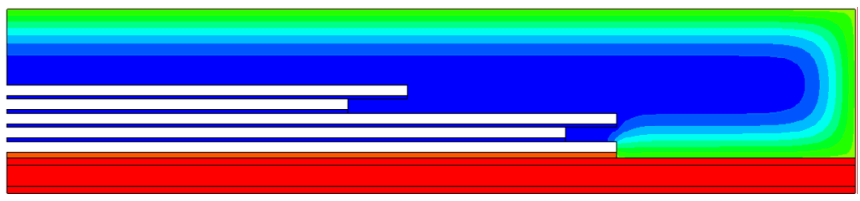

(b)

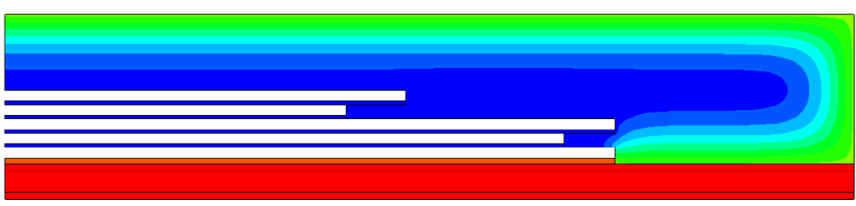

(c)

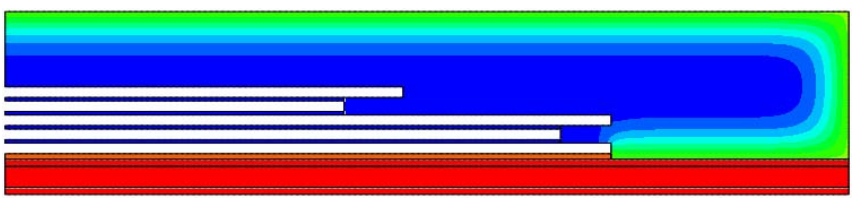

(d)

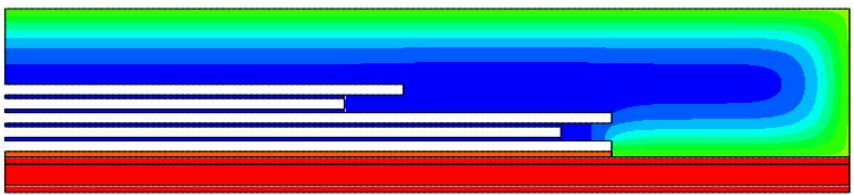

(e)

Fig. 6: Moisture distribution contours of soak under (a) MSL3 , (b) $45 \mathrm{hrs}-60^{\circ} \mathrm{C} / 60 \% \mathrm{RH}$, (c) $70 \mathrm{hrs}-60^{\circ} \mathrm{C} / 60 \% \mathrm{RH}$, (d) $25 \mathrm{hrs}-$ $85^{\circ} \mathrm{C} / 60 \% \mathrm{RH}$ and (e) $45 \mathrm{hrs}-85^{\circ} \mathrm{C} / 60 \% \mathrm{RH}$

Therefore, the moisture distribution at reflow temperature of $260^{\circ} \mathrm{C}$ after soak under MSL-3, $70 \mathrm{hrs}-60^{\circ} \mathrm{C} / 60 \% \mathrm{RH}$ and $45 \mathrm{hrs}-85^{\circ} \mathrm{C} / 60 \% \mathrm{RH}$ would be equivalent due to the same reflow process, inducing the equivalent vapor pressure, thermal stress and hygro-stress under these three conditions at high reflow temperature. The equivalent driving forces for cracking/delamination could achieve the equivalent failure mode and failure rate after soak under MSL-3, 70hrs$60^{\circ} \mathrm{C} / 60 \% \mathrm{RH}$ and $45 \mathrm{hrs}-85^{\circ} \mathrm{C} / 60 \% \mathrm{RH}$.

\section{Vapor Pressure Modeling}

To validate the equivalency of vapor pressure at the conditions of $70 \mathrm{hrs}-60^{\circ} \mathrm{C} / 60 \% \mathrm{RH}$ and MSL-3 during the reflow process, the vapor pressure modeling was performed based on the simplified micromechanics vapor pressure model $[18,19]$. The simplified micromechanics vapor pressure model was developed with the user-defined subroutine based on the widely used micromechanics vapor pressure model [14-17]. Fig. 7 shows the contours of vapor pressure distribution under MSL-3 and $45 \mathrm{hrs}-, 70 \mathrm{hrs}-60^{\circ} \mathrm{C} / 60 \% \mathrm{RH}$ at the reflow temperature of $260^{\circ} \mathrm{C}$. The vapor pressure is equivalent at the conditions of $70 \mathrm{hrs}-60^{\circ} \mathrm{C} / 60 \% \mathrm{RH}$ and MSL-3. Also as indicated by the results of vapor pressure modeling under $85^{\circ} \mathrm{C} / 60 \% \mathrm{RH}$, the vapor pressure is also equivalent under $45 \mathrm{hrs}-85^{\circ} \mathrm{C} / 60 \% \mathrm{RH}$ and MSL-3.

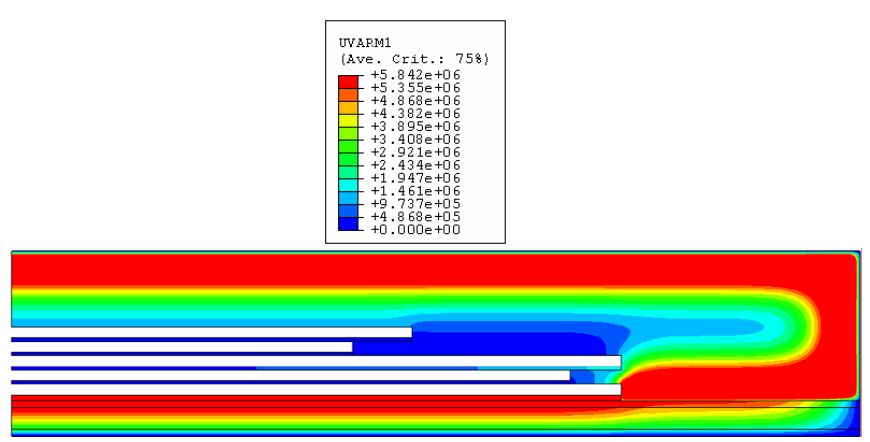

(a)

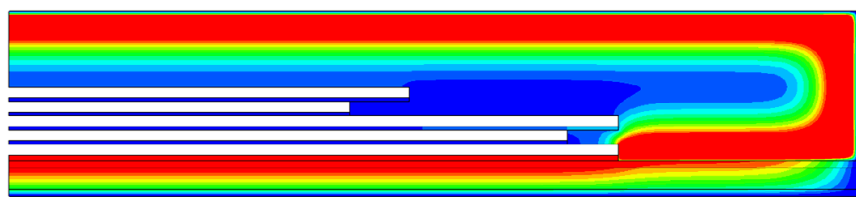

(b)

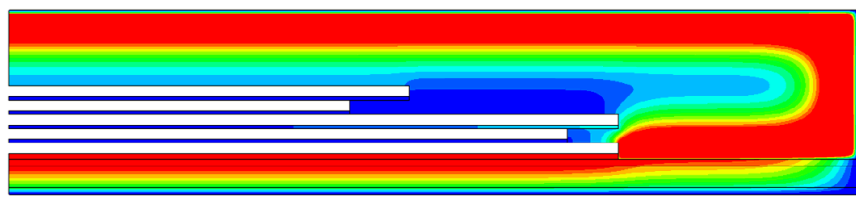

(c)

Fig. 7: Vapor pressure contours (at reflow temperature of $260^{\circ} \mathrm{C}$ ) of soak under (a) MSL-3 and (b) $45 \mathrm{hrs}-60^{\circ} \mathrm{C} / 60 \% \mathrm{RH}$, (c) $70 \mathrm{hrs}-60^{\circ} \mathrm{C} / 60 \% \mathrm{RH}$

\section{Experimental Validation}

\section{Failure Mode/Location Identification}

In order to validate the failure mode/location of the package under MSL-3, $70 \mathrm{hrs}-60^{\circ} \mathrm{C} / 60 \% \mathrm{RH}$ and $45 \mathrm{hrs}-$ $85^{\circ} \mathrm{C} / 60 \% \mathrm{RH}$, the failure analyses were conducted on the failed samples. As shown in Figs. 8, 9 and 10, the cracking/delamination occurred inside the bottom film for these three conditions, i.e., cohesive delamination. 


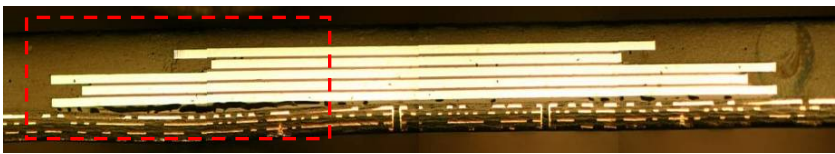

(a)

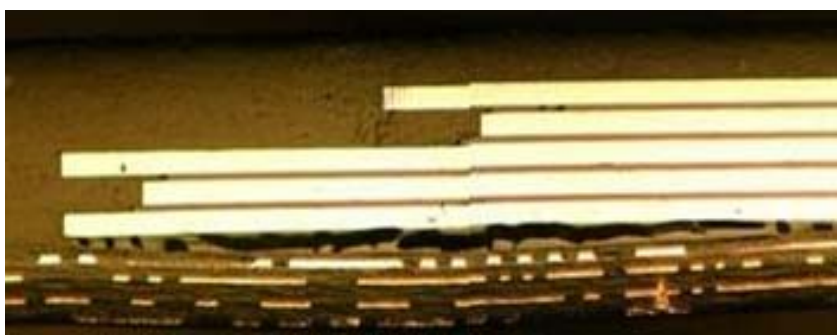

(b)

Fig. 8: (a) Cross-section view of the ultra-thin stacked-die CSP under MSL-3, (b) zoom-in view of highlighted region in (a)

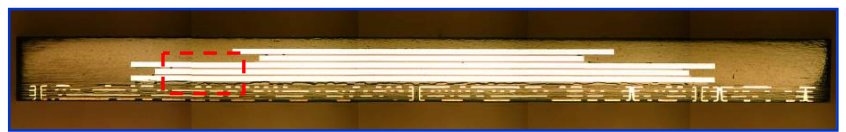

(a)

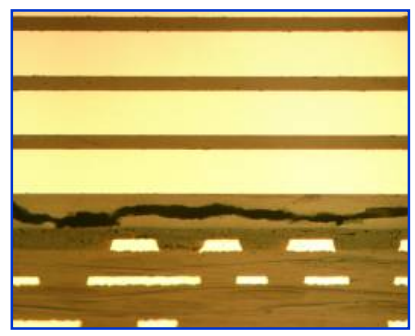

(b)

Fig. 9: (a) Cross-section view of the ultra-thin stacked-die CSP under $70 \mathrm{hrs}-60^{\circ} \mathrm{C} / 60 \% \mathrm{RH}$, (b) zoom-in view of highlighted region in (a)

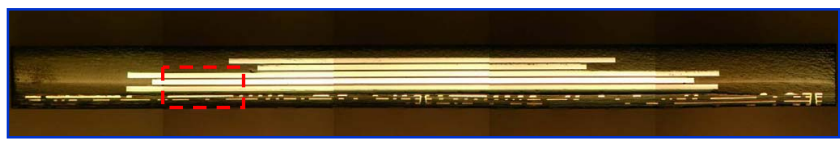

(a)

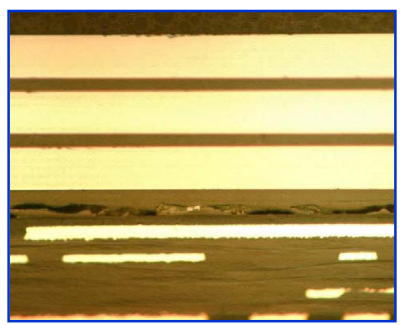

(b)

Fig. 10: (a) Cross-section view of the ultra-thin stacked-die CSP under $45 \mathrm{hrs}-85^{\circ} \mathrm{C} / 60 \% \mathrm{RH}$, (b) zoom-in view of highlighted region in (a)

\section{Determination of Equivalent Failure rate}

It is derived from the FEA that $70 \mathrm{hrs}-60^{\circ} \mathrm{C} / 60 \% \mathrm{RH}$ and $45 \mathrm{hrs}-85^{\circ} \mathrm{C} / 60 \% \mathrm{RH}$ are equivalent to the MSL-3. To validate the modeling results, the moisture/reflow tests were performed with the stacked-die CSP test vehicle under the conditions of MSL-3 and 30hrs-, 45hrs-, 60hrs-, 75hrs-, $88 \mathrm{hrs}-60^{\circ} \mathrm{C} / 60 \% \mathrm{RH}$ and $30 \mathrm{hrs}-, 45 \mathrm{hrs}-, 60 \mathrm{hrs}-85^{\circ} \mathrm{C} / 60 \% \mathrm{RH}$. After the moisture/reflow tests, the TSAM was used for the final inspection to determine the failure rate. The failure rate is defined as

$R=n_{f} / n_{t}$

where $R$ is the failure rate, $n_{f}$ is the number of failed samples, and $n_{t}$ is the number of total samples.

The failure rate under the condition of MSL-3 is $4.6 \%$, as shown in Fig. 11. The failure rates under the conditions of $60^{\circ} \mathrm{C} / 60 \% \mathrm{RH}$ but different times are also plotted in Fig. 11, they can be curve-fitted as

$\left\{\begin{array}{l}R=0 \text { if } t<57.2 \\ R=10^{0.05(t-57.2)} \text { if } t>57.2\end{array}\right.$

where $t$ is the soak time. By equaling the failure rates under $30^{\circ} \mathrm{C} / 60 \% \mathrm{RH}$ and $60^{\circ} \mathrm{C} / 60 \% \mathrm{RH}$, the soak time under $60^{\circ} \mathrm{C} / 60 \% \mathrm{RH}$ can be determined as $68.3 \mathrm{hrs}$ to be equivalency with MSL-3. Similarly, the failure rates under $85^{\circ} \mathrm{C} / 60 \% \mathrm{RH}$ but different times are plotted in Fig. 11, they can be curvefitted as

$\left\{\begin{array}{l}R=0 \text { if } t<36 \\ R=10^{0.05(t-36)} \quad \text { if } t>36\end{array}\right.$

By equaling the failure rates under $30^{\circ} \mathrm{C} / 60 \% \mathrm{RH}$ and $85^{\circ} \mathrm{C} / 60 \% \mathrm{RH}$, the soak time under $85^{\circ} \mathrm{C} / 60 \% \mathrm{RH}$ can be determined as $47 \mathrm{hrs}$ to be equivalency with MSL-3. The experimental moisture/reflow tests validated the new methodology and modeling analyses.

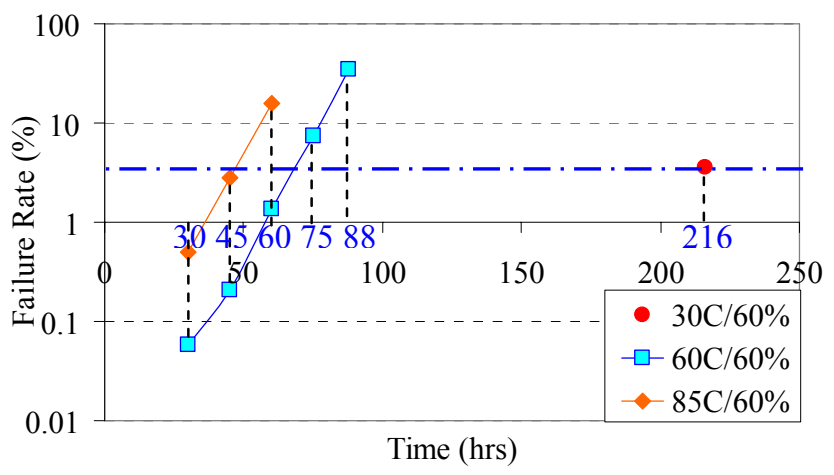

Fig. 11: Failure rates under $30^{\circ} \mathrm{C} / 60 \% \mathrm{RH}, 60^{\circ} \mathrm{C} / 60 \% \mathrm{RH}$ and $85^{\circ} \mathrm{C} / 60 \% \mathrm{RH}$

With the analyses of modeling results and experimental validation, it is therefore concluded that the conditions of $70 \mathrm{hrs}-60^{\circ} \mathrm{C} / 60 \% \mathrm{RH} 45 \mathrm{hrs}-85^{\circ} \mathrm{C} / 60 \% \mathrm{RH}$ are equivalent with MSL-3 in terms of global moisture distribution and vapor pressure, local moisture distribution and vapor pressure, failure rate, failure location and failure mode. 


\section{Conclusions}

This paper proposes a new methodology of accelerated moisture sensitivity test based on the equivalency of both local moisture concentration and overall moisture distribution. The new methodology can ensure the same failure mode/location and similar failure rate of cracking/delamination by the equivalency of local vapor pressure, interfacial adhesion as well as the thermal stress and hygro-stress. FEA modeling approaches were developed and applied for moisture diffusion and vapor pressure analysis of the package under various conditions of $30^{\circ} \mathrm{C} / 60 \% \mathrm{RH}$, $60^{\circ} \mathrm{C} / 60 \% \mathrm{RH}$ and $85^{\circ} \mathrm{C} / 60 \% \mathrm{RH}$. At $70 \mathrm{hrs}$ under $60^{\circ} \mathrm{C} / 60 \% \mathrm{RH}$ and $45 \mathrm{hrs}$ under $85^{\circ} \mathrm{C} / 60 \% \mathrm{RH}$, both the local moisture concentration at critical interface and overall moisture distribution of package become identical with that under MSL-3, indicating that $70 \mathrm{hrs}-60^{\circ} \mathrm{C} / 60 \% \mathrm{RH}$ and $45 \mathrm{hrs}-$ $85^{\circ} \mathrm{C} / 60 \% \mathrm{RH}$ is the equivalent soak time compared to MSL3. Such equivalencies of the test conditions are proven by the corresponding moisture/reflow sensitivity experiments and the failure analyses, indicating that the accelerated tests correlated well with the MSL-3 test. The methodology developed in this work can be extended to other packages.

\section{References}

1. B. Xie and X. Shi, and X.J. Fan, "Accelerated moisture sensitivity test methodology for stacked-die molded matrix array package", Proceedings of IEEE 9th Electronics Packaging Technology Conference, p.100104, December 2007

2. Joint Industry Standard J-STD-020, "Moisture/Reflow Sensitivity Classification for Plastic Integrated Circuit Surface Mount Devices", IPC (The Institute for Interconnecting and Packaging Electronic Circuits) and JEDEC (Joint Electron Device Engineering Council), 2004.

3. R. Shook, T. Conrad, V. Sastry and D. Steele, "Diffusion Model to Derate Moisture Sensitive Surface Mount IC's for Factory Use Conditions", IEEE Transaction on Components, Packaging and Manufacturing Technology, Vol. 19, No. 2, pp. 110-118, 1996.

4. R. Shook, R. Vaccaro and D. Gerlach, "Method for Equivalent Acceleration of JEDEC/IPC Moisture Sensitivity Levels", Annual International Reliability Physics Symposium, pp. 214-219, 1998.

5. S. Liu and Y. H. Mei, "Behavior of Delaminated Plastic IC Packages Subjected to Encapsulation Cooling, Moisture Absorption, and Wave Soldering", IEEE Transactions on Components, Packaging, and Manufacturing Technology, Part A, Vol. 18, No. 3, 1995.

6. A. A. O. Tay, and T. Y. Lin, "Moisture Diffusion and Heat Transfer in Plastic IC Packages", IEEE Transactions on Components, Packaging and Manufacturing Technology, Part A, Vol. 19, No. 2, pp.186-193, 1996.

7. A. A. O. Tay, and T. Y. Lin, "Influence of Temperature, Humidity and Defect Location on Delamination in Plastics Packages", IEEE Transactions on Components, Packaging and Manufacturing Technology, Part A, 22, no. 4, pp. 512-518, 1999.
8. X.J. Fan, "Mechanics of moisture for polymers: fundamental concepts and model study", 8th IEEE International Conference on Thermal and Mechanical Simulation and Experiments in Microelectronics and Microsystems, (EuroSimE), April 20-23, 2008

9. T. Y. Tee, C. L. Kho, D. Yap, C. Toh, X. Baraton and Z. W. Zhong, "Reliability Assessment and Hygroswelling Modeling of FCBGA with No-flow Underfill", Microelectronics Reliability, 43, pp. 741-749, 2003.

10. X.Q. Shi, Y.L. Zhang, W. Zhou, and X.J. Fan, "Effect of hygrothermal aging on interfacial reliability of silicon/underfill/FR-4 assembly", IEEE Transactions of Components and Packaging Technologies, 2008 (in press).

11.J. Zhou, "Analytical and Numerical Bound Analysis of Hygroscopic Swelling Characterization", Electronic Components and Technology Conference, pp. 734-739, 2006.

12. X.J. Fan, J. Zhou and A. Chandra "Package Structural Integrity Analysis Considering Moisture", Electronic Components and Technology Conference, 2008

13. G. Q. Zhang, W. D. V. Driel, and X. J. Fan, "Mechanics of Microelectronics", Springer, 2006.

14. X.J. Fan, J. Zhou, G. Q. Zhang and L. J. Ernst, "A Micromechanics Based Vapor Pressure Model in Electronic Packages", ASME Journal of Electronic Packaging, 127 (3), pp. 262-267, 2005.

15. X.J. Fan, G. Q. Zhang, W. V. Driel and L. J. Ernst, "Interfacial Delamination Mechanisms during Reflow with Moisture Preconditioning", IEEE Transactions on Components and Packaging Technologies, 2008 (in press).

16. X.J. Fan and T. B. Lim, "Mechanism Analysis for Moisture-induced Failures in IC packages", ASME 1999 International Mechanical Engineering Congress, IMECE/EPE-14, 1999.

17. X.J. Fan, "Moisture Related Reliability in Electronic Packging”, 2005/2006/2007/2008 ECTC Professional Development Course Notes, 2005/2006/2007/2008.

18. B. Xie, X.Q. Shi and X.J. Fan, "Sensitivity Investigation of Reflow Profile and Substrate Thickness on Wafer Level Film Failures in 3-D Chip Scale Packages by Finite Element Modeling", Electronic Components and Technology Conference, pp. 242-248, 2007.

19. D. Shi and X.J. Fan, "Wafer Level Film Selection for Stacked-die Chip Scale Packages", Electronic Components and Technology Conference, pp. 1731-1736, 2007. 